\title{
JOGOS EDUCATIVOS COMO AGENTE FACILITADOR NO PROCESSO DE APRENDIZAGEM DE QUÍMICA ${ }^{1}$
}

\author{
Eliane Cristina de Resende ${ }^{2}$ \\ Priscila Ferreira de Sales \\ Vássia Carvalho Soares \\ Meryene de Carvalho Teixeira \\ Claudimar Junker Duarte
}

\begin{abstract}
RESUMO
Este trabalho é um relato de experiência sobre o uso de jogos educativos como facilitador do processo de ensino e de aprendizagem em Química, que teve como objetivo despertar o interesse dos estudantes e encontrar alternativas capazes de ajudá-los a compreender as transformações Químicas que ocorrem no mundo de forma abrangente e integrada. Para tanto, discentes dos cursos técnicos integrados e superiores do Instituto Federal de Minas Gerais Campus Bambuí elaboraram jogos educativos abordando conceitos de Química. Uma banca de jurados, composta por servidores de diversas áreas do Instituto, avaliou de forma criteriosa os jogos educativos. Ao final, os estudantes responderam um questionário, para avaliar de forma qualitativa a percepção dos mesmos, quanto ao aprendizado dos conceitos abordados e dificuldades durante o processo. Observou-se que a elaboração dos jogos educativos contribuiu para o aprendizado dos conteúdos abordados e mostrou-se importante para estimular as relações cognitivas, afetivas e sociais dos estudantes.
\end{abstract}

Palavras-chave: Atividade lúdica. Integração. Ferramenta pedagógica.

\section{EDUCATIONAL GAMES AS A FACILITATING AGENT IN THE CHEMISTRY LEARNING PROCESS}

\begin{abstract}
This work is an experience report on the use of educational games as a facilitator of the teaching and learning process in Chemistry, which aimed to arouse the interest of students and find alternatives capable of helping them to understand the chemical transformations that occur in the world in a comprehensive and integrated way. In order to achieve this, students from integrated technical courses and college at the Federal Institute of Minas Gerais - Campus Bambuí developed educational games addressing Chemistry concepts. A panel of judges, composed of colleagues from different areas of the Institute, carefully, evaluated the

\footnotetext{
${ }^{1}$ Como citar este artigo:

RESENDE, E. C.de et al. Jogos educativos como agente facilitador no processo de aprendizagem de Química. ForScience, Formiga, v. 8, n. 2, e00839, jul./dez. 2020. DOI: 10.29069/forscience.2020v8n2.e839.
}

${ }^{2}$ Autor para correspondência: Eliane Cristina de Resende, e-mail: eliane.resende@ifmg.edu.br
\end{abstract}


educational games. At the end, students answered a questionnaire to qualitatively assess their perception, regarding the learning of the concepts addressed and difficulties during the process. It was observed that the elaboration of educational games contributed to the learning of the contents covered and proved to be important to stimulate students' cognitive, affective and social relationships.

Keywords: Ludic activity. Integration. Pedagogical tool.

\section{INTRODUÇÃO}

É incontestável o importante papel da Química no desenvolvimento tecnológico com contribuições específicas de caráter social, ambiental e econômico, bem como a interação dos estudantes com as tecnologias advindas do uso desta ciência. Contudo, o desinteresse dos estudantes por essa disciplina tem se mostrado um grande desafio para os docentes. Dentre as disciplinas que compõem a matriz curricular, a Química é reportada como uma das mais difíceis e complicadas, visto que muitas vezes se encontra arraigada a concepções tradicionais que considera que o processo de ensino e de aprendizagem acontece por meio da repetição e memorização de fórmulas, conceitos e equações, que por sua vez a afasta da contextualização com o ambiente em que se vive (OLIVEIRA; SOARES, 2005). Entende-se que esta realidade é desmotivadora, despertando pouco interesse por parte dos estudantes em aprender e relacionar o conteúdo estudado ao cotidiano.

Desta forma, a busca por novas alternativas e metodologias auxiliares que contribuam no processo de ensino e de aprendizagem têm sido cada vez mais necessária entre os professores. De acordo com as diretrizes estabelecidas nos Parâmetros Curriculares Nacionais (PCN), o ensino da Química deve ser pautado de forma a permitir a construção de uma visão de mundo mais articulada e menos fragmentada, contribuindo para que o estudante se veja como participante de um mundo em constante transformação (BRASIL, 1998). Corroborando com essas diretrizes, a nova Base Nacional Comum Curricular (BNCC), segue a mesma tendência, orientando que a disciplina seja trabalhada a partir de problemas e fenômenos do dia a dia, oferecendo condições aos jovens de participar, de forma crítica, dos debates do mundo contemporâneo (BRASIL, 2017).

Neste contexto, o uso de atividades lúdicas pode tornar o processo de aprendizagem mais dinâmico, permitindo ao estudante uma participação ativa na construção do conhecimento, estimulando a criatividade e o desenvolvimento de habilidades, que por sua vez contribuem para sua motivação e autoestima, favorecendo o desenvolvimento cognitivo, psicológico, social e formativo, atendendo assim às novas tendências da educação. Há evidências históricas que os 
jogos sempre estiveram presentes na vida do ser humano, conforme o filósofo Platão (427-348 a.C) que destacava sobre a importância de se "aprender brincando" (CUNHA, 2012). Felício e Soares (2018) argumentaram sobre o uso do lúdico na educação, afirmando que:

\begin{abstract}
No sentido que estamos propondo, o lúdico envolveria os jogos ou atividades que atendam aos princípios educacionais mediados por uma intencionalidade lúdica do professor que em suas propostas pedagógicas inclua atividades que permitam a invenção de uma liberdade regrada por meio de ações que respondam aos objetivos educativos. Desta forma, na maneira como as regras aparecem, implícitas ou explicitamente é que se definem os tipos de atividades lúdicas. E nesta perspectiva defendemos o uso do lúdico para ensinar ou avaliar a aprendizagem de conceitos químicos ou de qualquer outra natureza, na formação básica e também na profissional (FELÍCIO; SOARES, 2018).
\end{abstract}

A exploração de aspectos lúdicos pode colaborar para o desenvolvimento intelectual, social e afetivo, potencializando a construção do conhecimento pelos estudantes. Contudo, cabe ressaltar que o emprego deste aspecto não substitui o papel do docente no processo de ensino, sendo fundamental que os educadores estejam atentos sobre a forma de conduzir e empregar essas ferramentas na educação. A importância dos educadores conhecerem alguns princípios inerentes ao uso dos recursos lúdicos no ensino, no intuito de iniciar uma dada intencionalidade educativa, no que se refere a elaborar jogos e brincadeiras que possam auxiliar na reflexão sobre a sua prática educativa e desenvolver atividades que possam atender às necessidades formativas de seus estudantes (MESSEDER NETO; MORADILO, 2016).

Para Brougère; Duflo; Huizinga (1998; 1997; 2005 apud CUNHA, 2012) a utilização de recursos lúdicos, pode ser um instrumento adequado para se trabalhar a motivação e o interesse, considerando a natureza destas atividades e suas relações intrínsecas ao ser humano, desde que empregada de maneira intencional e compartilhada com os estudantes. Felício e Soares (2018) refletiram sobre a necessidade de compromisso dos docentes ao empregar recursos lúdicos, uma vez que devem ser elaborados e voltados ao desenvolvimento de habilidades cognitivas e formação integral do ser humano.

Uma série de reflexões teóricas importantes, sobre as definições de atividades lúdicas e jogos foi descrita por Soares (2016). Considerando a grande quantidade de definições, o autor defende a ideia de que o uso da palavra JOGO ou LÚDICO para qualquer atividade que tenha relação com o uso de atividades lúdicas é bastante adequada, uma vez que todo jogo é considerado uma atividade lúdica, exatamente pela sua essência, pautada na diversão.

Desta forma, a utilização de jogos no ambiente escolar tem se mostrado como uma estratégia possível para a construção de conhecimento, tanto porque permite ensinar conceitos quanto facilita a fixação de conteúdos, possibilitando ao estudante atuar ativamente neste 
processo de aprendizagem. Cunha (2012) destacou os jogos como importante recurso para as aulas de Química, permitindo a aprendizagem mediante a experiência e a atividade dos estudantes, sendo relevante para o conhecimento e desenvolvimento de diferentes habilidades nos campos afetivo e social.

Com base nas definições de Brougère (1998 apud SOARES, 2016) o jogo está ligado ao prazer e ao divertimento, enquanto o aspecto educativo possibilita o acesso ao conhecimento. Contudo este acesso parece não se dar de maneira lúdica. Segundo Brougère (1998 apud SOARES, 2016) há um paradoxo do jogo educativo quando não se consegue encarar adequadamente o jogo sobre dois vieses, um ligado à ludicidade e outro ligado à educação. Desta forma, há necessidade de existir no jogo, um equilíbrio entre as funções: lúdica e educativa (KISHIMOTO, 1996). Durante a elaboração de jogos educativos, deve-se preservar a função lúdica que propicia diversão, prazer e até mesmo desprazer quando escolhido voluntariamente e de forma equilibrada a função educativa, relacionada à apreensão de conhecimentos, habilidades e saberes.

Quando bem empregada, a atividade lúdica mostra-se como uma importante ferramenta pedagógica sendo uma forma alternativa e eficaz capaz de integrar os estudantes em um ambiente de ensino que perpassa pela sensibilização e humanização, tornando significativo o processo de aprendizagem e aquisição de conhecimento. $\mathrm{O}$ uso de jogos tem se destacado como instrumento motivador neste processo de aprendizagem de conhecimentos químicos, como uma metodologia ativa centrada no aprendiz, na medida em que propõe estímulo ao interesse do estudante e as vantagens de sua utilização ultrapassam a simples assimilação de conceitos e fórmulas.

Muitos trabalhos destacaram as contribuições das atividades lúdicas como facilitador no processo de ensino e aprendizagem, percebesse que o número de trabalhos envolvendo essa temática tem aumentado progressivamente a cada ano (OLIVEIRA; SOARES, 2005; NASCIMENTO, PORTO, 2016; SOARES, 2008; CUNHA， 2012; SILVA; LIMA; FERREIRA, 2016; GARCEZ; SOARES, 2017; FELÍCIO; SOARES, 2018; NASCIMENTO; VIEIRA; ARAÚJO; MELO; VIANA, 2018; REZENDE; SOARES, 2019).

Nascimento, Vieira, Araújo, Melo, Viana (2018) relataram sobre a importância do desenvolvimento, aplicação e a avaliação de um jogo didático denominado Ludo das Ligações Químicas, fundamentado na teoria de George Kelly, que tem como base a construção do conhecimento em etapas conhecidas como Ciclo da Experiência Kellyana. Sobre a ótica dos pesquisadores tal intervenção caracterizou-se como uma pesquisa-ação, que possibilitou aos participantes condições de investigar sua própria prática de uma forma crítica e reflexiva. De 
acordo com os resultados, os autores relataram que foi notória a importância da utilização dos jogos didáticos no processo de ensino e de aprendizagem, pois os estudantes e professores interagiram de maneira positiva e construtiva. A função educativa do jogo foi observada, verificando-se que o mesmo favoreceu a aquisição e retenção de conhecimentos, em clima de alegria e prazer.

A elaboração e aplicação de um jogo denominado "Descobrindo os Elementos Químicos", com estudantes de Licenciatura em Química da Universidade Federal de Campina Grande foi descrita, a fim de identificar as percepções, bem como o embasamento teórico que os estudantes traziam desde a época do ensino médio em relação à Tabela Periódica (SILVA; LIMA; FERREIRA, 2016). Os autores destacaram a importância do estudante como agente ativo e participativo na construção do conhecimento e, de acordo com os resultados, eles perceberam que antes do jogo $57 \%$ dos discentes tiveram dificuldade ou não souberam responder ao questionário aplicado. Contudo, após o emprego do jogo, 95\% dos discentes afirmaram que não tinham conhecimento sobre os assuntos abordados e que o jogo favoreceu a compreensão dos conceitos químicos, uma vez que conseguiram assimilar os conteúdos abordados na atividade (SILVA; LIMA; FERREIRA, 2016).

Nascimento e Porto (2016) descreveram sobre a criação e análise, em conjunto com os estudantes, do jogo "Memória Química" adaptado do tradicional Jogo de Memória, como facilitador para o processo de assimilação de estudantes com dificuldades de aprendizagem. Embasados pela teoria de Vygotsky que orienta a conhecer o estudante desde a sua história, os autores perceberam que a participação do estudante na construção do jogo proporcionou um maior conhecimento dos conceitos químicos. Os autores observaram o quanto os estudantes desenvolveram várias habilidades, como física, social, afetivo, iniciativa, trabalho em equipe e o desenvolvimento cognitivo de forma lógica e coerente, além da importância do planejamento para ter sucesso na aplicação do jogo.

De modo geral, os jogos, assim como qualquer outro recurso didático, não podem ser utilizados para substituir as aulas convencionais. Entretanto podem ser concebidos como uma metodologia efetiva de apoio ao professor, podendo tornar o estudante protagonista do próprio aprendizado e revelar novas habilidades, como trabalhar em equipe, superar desafios, respeitar regras e estabelecer estratégias que aguçam a criatividade.

Desta forma, motivados pelo interesse em construir novas formas de pensamento e possibilitar o desenvolvimento de novas habilidades dos estudantes, os docentes do Núcleo de Química do Instituto Federal de Minas Gerais - Campus Bambuí, têm desenvolvido com os estudantes que cursam disciplinas de Química um projeto de ensino com o objetivo de permitir 
ao estudante vivenciar de forma lúdica os conhecimentos em Química, buscando integrar motivação, criatividade e aprofundamento de conteúdos trabalhados em sala de aula.

\section{METODOLOGIA}

Os docentes do núcleo de Química do Instituto Federal de Minas Gerais - Campus Bambuí, inspirados no Encontro Nacional de Jogos e Atividades Lúdicas no Ensino de Química, o JALEQUIM, promoveram um evento denominado "II JALEQUIN" (Jogos, Atividades Lúdicas e Experimentos Químicos Interativos), buscando criar situações de aprendizagem alternativas, mais dinâmicas e efetivas, contemplando a integração da Química por meio da inserção de atividades lúdicas. $\mathrm{O}$ evento foi dividido em duas etapas: elaboração de jogos educativos pelos estudantes e em um segundo momento a apresentação dos jogos a uma banca de jurados e para a comunidade acadêmica e externa na Quadra de Esportes do IFMG.

O evento foi divulgado no site oficial da instituição, nas redes sociais e e-mails. A FIG. 1 apresenta o convite para o evento e a mensagem de divulgação: "O núcleo de Química convida a todos para prestigiarem o II JALEQUIN - Jogos, Atividades Lúdicas e Experimentos Químicos Interativos. Será sábado, 20 de outubro a partir das 08:30 no campus Bambuí (quadra atrás do poliesportivo). Venha e traga toda família!! Chame a criança que mora em você para brincar com as crianças que você ama!!!”

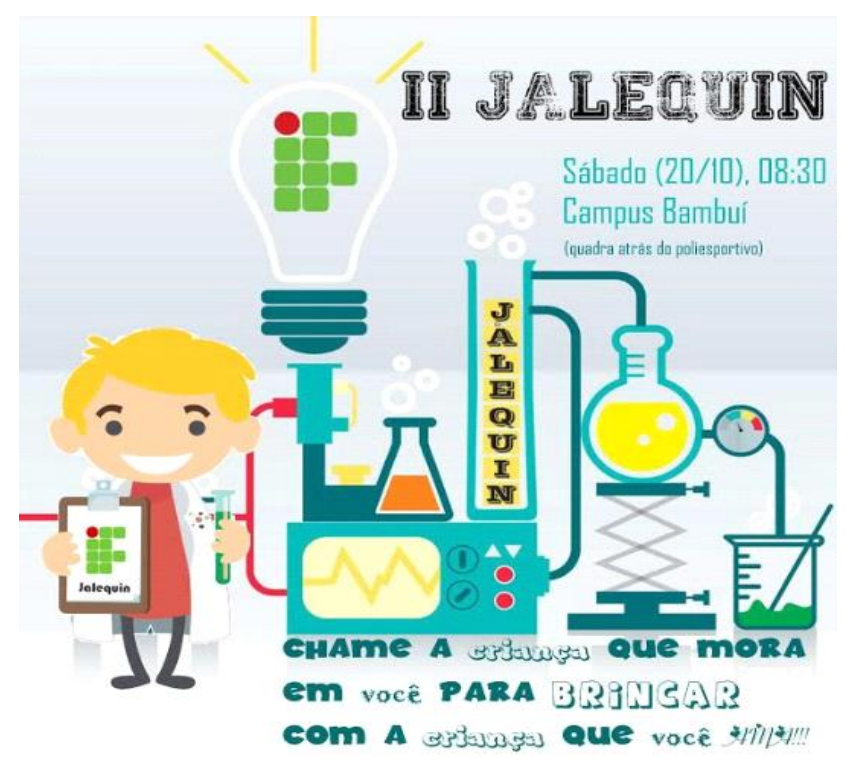

Figura 1 - Ilustração do convite de divulgação do evento "II JALEQUIN".

Fonte: Dos autores, (2018). 
A ação contou com a participação dos estudantes que cursaram disciplinas de química, ofertadas aos cursos técnicos integrados ao ensino médio (Química I, Química II e Química III) ou dos cursos superiores (Química Geral, Laboratório de Química Geral, Química Analítica, Laboratório de Química Analítica, Química Orgânica e Físico-Química). Os estudantes foram divididos em quatro equipes.

Inicialmente foi definido um conjunto de orientações (QUADRO 1) as quais foram disponibilizadas na página oficial do evento.

1) As equipes participantes deverão apresentar no dia do evento as seguintes atividades, que necessitam obrigatoriamente estar relacionadas aos conteúdos químicos. As atividades podem ser criadas ou adaptadas de jogos já existentes.

Atividade 1 - jogo de cartas

Exemplos de jogos para adaptação: UNO, buraco, truco, pôquer, etc..

Atividade 2 - jogo de tabuleiro

Exemplos de jogos para adaptação: dama, xadrez, Imagem e Ação, Jogo da Vida, Banco Imobiliário, etc..

Atividade 3 - jogo de rua

Exemplos de jogos para adaptação: queimada, rouba-bandeira, pique (variados), corre cotia, etc..

Atividade 4 - jogos de mãos

Exemplos de jogos para adaptação: adoleta, fui à China, soco bate vira, etc..

2) Pelo menos um jogo, relacionado à atividade 1 ou à atividade 2 , deverá ser elaborado com materiais sustentáveis.

3) No caso de adaptação de jogos, não é necessário seguir à risca as regras do jogo de origem.

4) Não há necessidade de produção dos jogos em tamanho real, sendo permitido tabuleiros/cartas/peões ampliados ou reduzidos em relação ao original. Podendo até mesmo utilizar os próprios participantes fantasiados/caracterizados.

5) No final do evento, os jogos deverão ser entregues aos professores organizadores. No caso de jogos de rua e jogos de mão, deverão ser entregues as regras e orientações dos jogos (se houver).

6) É necessário entregar uma cópia das regras dos jogos aos jurados

7) É permitido e deve ser respeitado que membros de outras equipes e visitantes participem dos jogos.

8) Não serão permitidas agressões físicas, verbais ou prejuízos materiais.

9) As equipes deverão estar caracterizadas, com cores distintas, as quais devem ser postadas no grupo do evento.

10) A equipe será responsável pela limpeza do local após o evento.

11) É PROIBIDO qualquer tipo de conteúdo pornográfico, religioso ou político bem como apologia às drogas.

12) Nenhuma das atividades poderá ser apresentada na forma digital.

Quadro 1- Conjunto de regras definidas para as apresentações dos jogos e atividades no "II JALEQUIN". Fonte: Dos autores, (2018). 
A fim de contribuir com o processo de construção do conhecimento pelos estudantes, garantir a integridade dos conceitos químicos abordados bem como assegurar o equilíbrio entre a função lúdica e a função educativa dos jogos, o processo de elaboração de todos os jogos foi examinado pelos professores norteadores do projeto. Este procedimento foi realizado de forma conjunta com os estudantes, na tentativa de oferecer a oportunidade para reflexão sobre o tema abordado, possibilitando o progresso na formação do estudante. Ainda nessa etapa foi verificado se os materiais produzidos pelas equipes tinham muitos erros. Segundo Cunha (2012) o erro faz parte do processo de aprendizagem e deve ser entendido como uma oportunidade para construção de conceitos.

No dia da apresentação, cada atividade proposta foi avaliada por uma banca composta por 3 servidores de diversas áreas, dentre eles um pedagogo. Os itens avaliados foram padronizados para todas as equipes por meio de um barema que compreendia os seguintes critérios:
a) originalidade;
b) jogabilidade/fluidez do jogo;
c) regras claras/fáceis;
d) criatividade;
e) organização da equipe;
f) caracterização da equipe;
g) correlação com a Química/embasamento teórico;
h) animação/dinâmica da equipe;
i) domínio do jogo pela equipe;
j) estética.

Para cada item foi atribuída uma nota máxima de 10 pontos, totalizando 100 pontos. Para preservar a imparcialidade das notas nenhum professor organizador participou da avaliação e pontuação das equipes.

\section{RESULTADOS E DISCUSSÕES}

\subsection{A abordagem Química nos jogos desenvolvidos e a contextualização do processo de ensino e de aprendizagem}


A TAB. 1 resume os conteúdos químicos contemplados nas diferentes modalidades de jogos de cada equipe.

Tabela 1 - Descrição dos conteúdos químicos abordados em cada modalidade de jogo

\begin{tabular}{|c|c|c|}
\hline Equipe & $\begin{array}{c}\text { Modalidade } \\
\text { de jogo } \\
\end{array}$ & Conteúdos químicos \\
\hline \multirow{4}{*}{$\mathbf{A}$} & Cartas & Conteúdos de Bioquímica \\
\hline & Mãos & Elementos químicos \\
\hline & Rua & $\begin{array}{l}\text { Vidrarias de laboratório: empregos e funções; elementos } \\
\text { químicos e tabela periódica; noções de atomística: partículas } \\
\text { subatômicas e funções inorgânicas }\end{array}$ \\
\hline & Tabuleiro & Tabela periódica \\
\hline \multirow{4}{*}{ B } & Cartas & Períodos e famílias da Tabela Periódica \\
\hline & Mãos & Formação de micelas e eletronegatividade \\
\hline & Rua & Queimiquim (jogo de queimada) \\
\hline & Tabuleiro & $\begin{array}{l}\text { Board Game Químico (Perguntas diversificadas sobre } \\
\text { Química) }\end{array}$ \\
\hline \multirow{4}{*}{$\mathbf{C}$} & Cartas & Definição e ordem de eletronegatividade \\
\hline & Mãos & $\begin{array}{l}\text { Nomenclatura de prefixos e ramificações em Química } \\
\text { Orgânica }\end{array}$ \\
\hline & Rua & Massa dos elementos químicos \\
\hline & Tabuleiro & Propriedades Físico-Químicas de metais e ametais \\
\hline \multirow{4}{*}{$\mathbf{D}$} & Cartas & $\begin{array}{l}\text { Ânions, cátions, reações Químicas; formação de ácidos e de } \\
\text { sais }\end{array}$ \\
\hline & Mãos & Símbolo e posição dos elementos na Tabela Periódica \\
\hline & Rua & $\begin{array}{l}\text { Radicais: propriedades e reações. Halogenação de alcanos. } \\
\text { Ligações Químicas e estabilidade }\end{array}$ \\
\hline & Tabuleiro & $\begin{array}{l}\text { Elementos Químicos: símbolos e propriedades; noções de } \\
\text { atomística; funções inorgânicas: propriedades e } \\
\text { nomenclatura; modelos atômicos. }\end{array}$ \\
\hline
\end{tabular}

Fonte: Dos autores, (2020)

Conforme apresentado na TAB. 1, observa-se que as equipes buscaram contemplar uma vasta quantidade de conteúdos químicos nas atividades propostas, sinalizando que o evento despertou o interesse dos estudantes pela Química. A realização do evento permitiu com que os estudantes integrassem os conteúdos químicos estudados em sala de aula aos jogos confeccionados.

Na FIG. 2 são apresentadas imagens de alguns jogos, que foram apresentados durante o evento. A divisão dos estudantes em equipes contribuiu para o desenvolvimento de relações interpessoais entre dos membros das equipes, permitindo que os estudantes se organizassem para apresentar de forma coerente os conteúdos, evidenciando que o processo de ensino e de 
aprendizagem é algo complexo e motivador, uma vez que é concebido de maneiras distintas e envolve diferentes agentes no processo.

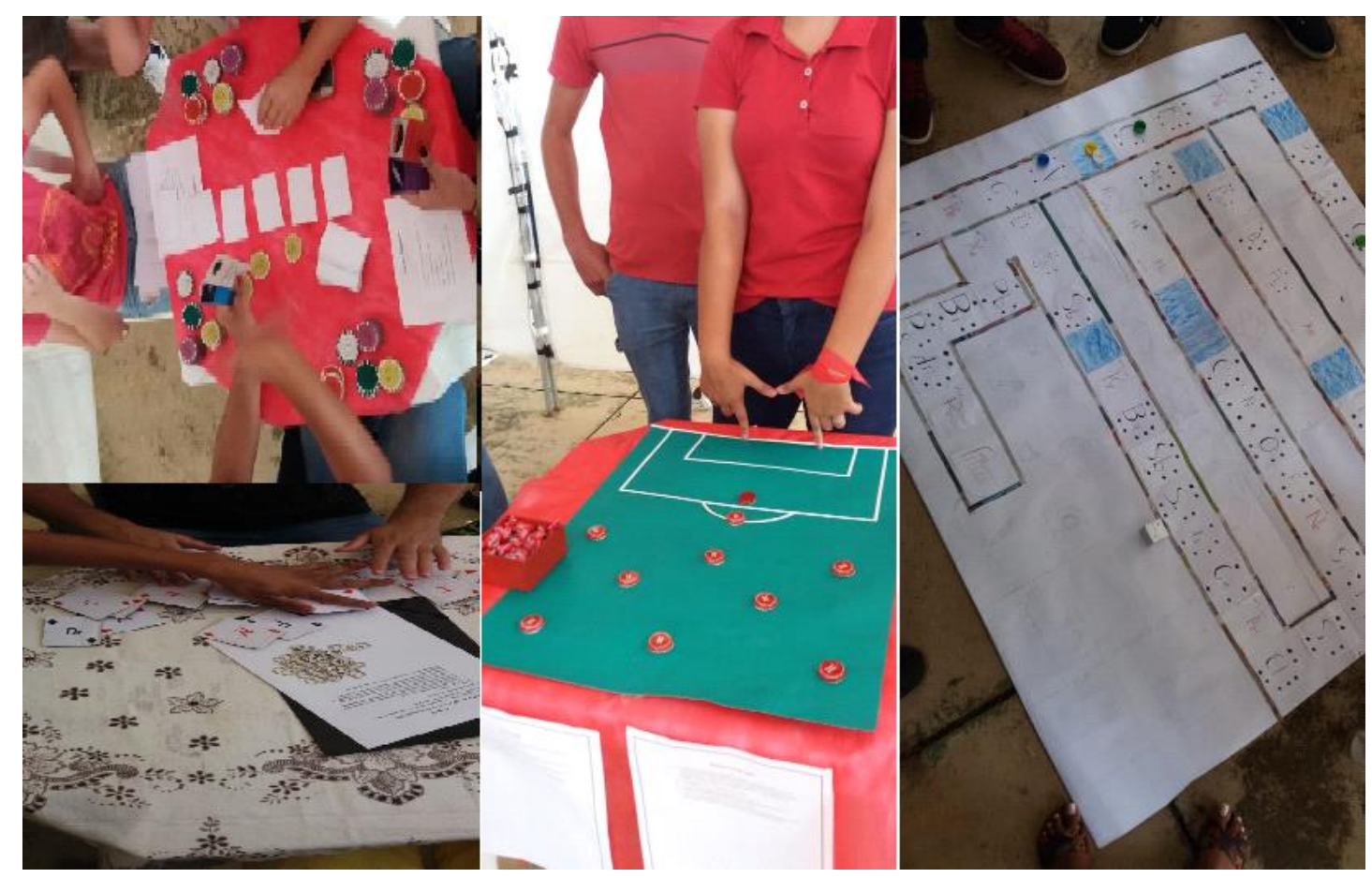

Figura 2 - Jogos confeccionados e apresentados no evento "II JALEQUIN". Fonte: Dos autores, (2020).

Alguns estudantes relataram durante as aulas que, após o evento, apresentaram maior facilidade em assimilar os conceitos construídos ao longo da elaboração dos jogos e vinculálos às abordagens em sala de aula.

A adequação dos conteúdos químicos às regras dos jogos, associada ao clima de competição amigável entre as equipes contribuíram para que os jogos elaborados preservasse o elo entre as funções lúdica e educativa, permitindo um equilíbrio entre a brincadeira e o desenvolvimento de conhecimentos, habilidades e saberes, conforme abordado por Kishimoto (1996).

O II JALEQUIN permitiu aos estudantes vivenciar experiências que contribuíram para mudanças na estrutura cognitiva do mesmo, facilitando a compreensão dos conceitos químicos. Vale ressaltar quatro etapas de aprendizagem observadas durante o desenvolvimento do II JALEQUIN, que compreendem:

- Antecipação: os estudantes receberam o convite para participar do evento (II JALEQUIN). O objetivo foi permitir com que os mesmos buscassem em suas 
concepções, ideias relevantes para compreender o evento, iniciando desta forma o processo de aprendizagem.

- Organização: os estudantes divididos nas quatro equipes se prepararam para participar ativamente do evento. Nesta etapa eles se organizaram a fim de desenvolver os jogos, buscando informações sobre o assunto através da interação com os colegas, pesquisas na internet, anotações do caderno, permitindo com que o estudante desenvolvesse e passasse a ter um conhecimento mais abrangente do que possuíam anteriormente. Em seguida apresentaram aos docentes os protótipos dos jogos elaborados obedecendo às regras apresentadas de forma antecipada.

- Confirmação ou desconfirmação: de forma associada, os docentes levaram os estudantes a refletir a respeito de suas concepções. Os docentes puderam contribuir com os estudantes a fim de verificar a existência de erros conceituais, sendo que esta etapa foi de extrema importância para a validação e construção dos conceitos e conteúdos abordados pelos estudantes.

- Revisão Construtiva: após a intervenção dos professores, os estudantes fizeram uma revisão de seus conhecimentos, puderam sedimentá-los e através do evento vivenciando essa experiência motivadora de aprendizagem.

Diante deste contexto, tornou-se evidente que a disciplina de Química pode ser trabalhada de maneiras distintas e que é possível explorar a capacidade comunicativa e habilidades que muitas vezes são desconsideradas dentro do ambiente de sala de aula. Pode-se, ainda, verificar que a contextualização do processo de ensino e aprendizagem é algo abrangente na prática docente, o que faz com o docente possa buscar cada vez mais o aprimoramento dessa ciência e a realização de novos eventos dentro da Instituição de Ensino.

\subsection{Resultados quantitativos e a classificação das equipes}

Na TAB. 2 a seguir é descrito o resultado final, com a média das notas atribuídas pela avaliação dos jurados com base no barema empregado. 
Tabela 2 - Resultado final da avaliação das equipes nas diferentes modalidades e classificação das equipes envolvidas no evento

\begin{tabular}{ccccccc}
\hline Equipe & $\begin{array}{c}\text { Jogo de } \\
\text { mão }\end{array}$ & $\begin{array}{c}\text { Jogo de } \\
\text { tabuleiro }\end{array}$ & $\begin{array}{c}\text { Jogo de } \\
\text { cartas }\end{array}$ & $\begin{array}{c}\text { Jogo de } \\
\text { rua }\end{array}$ & Total & Classificação \\
\hline $\mathrm{A}$ & 85,8 & 93,0 & 97,2 & 75,3 & 351,3 & $3^{\mathbf{o}}$ \\
\hline $\mathrm{B}$ & 88,3 & 91,5 & 93,5 & 84,3 & 357,6 & $2^{\mathbf{o}}$ \\
\hline $\mathrm{C}$ & 94,8 & 89,8 & 82,8 & 93,0 & 360,4 & $1^{\mathbf{o}}$ \\
\hline $\mathrm{D}$ & 59,3 & 93,5 & 96,4 & 76,8 & 326,0 & $4^{\mathbf{o}}$ \\
\hline \multicolumn{7}{c}{ Fonte: Dos autores, (2020) } \\
\end{tabular}

Conforme pode ser observado na TAB. 2, de forma geral, todas as equipes foram bem avaliadas pelos jurados, conseguindo no mínimo $81,5 \%$ da nota total, evidenciando assim o comprometimento dos estudantes no desenvolvimento das tarefas propostas. Pode-se inferir que as equipes que tiveram melhor desempenho na avaliação dos jurados foram aquelas que melhor se organizaram e trabalharam em conjunto, além de apresentar uma abordagem dos conceitos químicos, mais coerente e criativa. Vale reportar que os estudantes envolvidos, independentemente de sua classificação, mostraram-se motivados e empenhados durante todo o processo em trazer para os visitantes uma abordagem dos conteúdos químicos de maneira simplificada e acessível, permitindo ainda uma atuação ativa na assimilação dos conceitos.

\subsection{Percepções dos participantes das equipes após o evento}

Foi aplicado um questionário que foi respondido de forma voluntária por integrantes que pertenciam a equipes distintas, de forma a analisar a percepção dos estudantes após o processo. Nesse contexto, pretendia-se verificar de forma exploratória se o uso do jogo pôde ser validado com relação aos objetivos pretendidos. No QUADRO 2 é apresentado o questionário com as perguntas e respostas que foram condensadas e contextualizadas de modo a contemplar o máximo de descrições possíveis.

\section{1- O que mais te chamou atenção no evento?}

“A exigência de que um dos jogos fosse sustentável, pois apesar de dar um pouco de trabalho, foi muito bom para nos conscientizar de que menos é mais".

"A interação entre as equipes, a união das mesmas e animação dos participantes".

"A possibilidade de aprendizagem da Química de forma divertida"

2- Quais as dificuldades encontradas para a confecção dos jogos?

"Alguns estudantes inicialmente não se empenharam como deveria, dificultando para conseguir os materiais e montar os jogos".

"Tivemos dificuldade para desenvolver a criatividade para produzir algo novo e divertido, bem como a falta de materiais essenciais".

3- Como o evento contribuiu para a consolidação do conhecimento em Química? 
"A confecção dos jogos contou com muita pesquisa, se mostrando bastante agregador".

"Fizemos diversas pesquisas para avaliar quais os conteúdos que poderiam ser contemplados de maneira lúdica, descontraída e fluida o que contribuiu para nossa aprendizagem".

"Ver a Química junto com brincadeiras do cotidiano e jogos populares permitiu entender como ela está presente no dia a dia e que é algo essencial".

"Os jogos nos incentivaram a querer aprender mais até para colocar à prova os conhecimentos em coisas rotineiras".

"O evento contribuiu para reforçar os conhecimentos que são construídos em sala de aula".

Quadro 2 - Questionário aplicado e respostas condensadas de modo a contemplar o máximo de descrições.

Fonte: Dos autores, (2020).

A partir dos relatos pode-se verificar que a experiência de criação dos jogos mostrou grandes mudanças na percepção dos estudantes em relação à disciplina de Química, ficando evidente a importância do lúdico como ferramenta metodológica. Pode-se perceber que os estudantes das séries iniciais mostraram-se interessados para o conhecimento de novos conteúdos. Destacamos ainda que através da proposta desenvolvida, houve o estímulo a criatividade; a socialização além de favorecer a compreensão dos conceitos de Química.

\section{CONSIDERAÇÕES FINAIS}

A elaboração de jogos educativos permitiu aos estudantes a integração dos conteúdos químicos com as atividades lúdicas propostas, favorecendo assim o processo de ensino e de aprendizagem da referida disciplina, como relatado pelos estudantes por meio do questionário. Evidencia-se ainda que o desenvolvimento deste trabalho mostrou-se importante para estimular a criatividade e as relações cognitivas, afetivas e sociais dos mesmos.

A inclusão do estudante como agente efetivo na construção dos jogos despertou o interesse do mesmo, possibilitando o desenvolvimento de habilidades tais como o trabalho em equipe, superação de desafios, respeito às regras impostas e o estabelecimento de estratégias criativas.

Após o evento foi observado que os estudantes se mostraram mais motivados, sendo capazes de associar a aprendizagem durante o evento às situações descritas em sala de aula e evidenciadas no cotidiano.

O evento promovido pelo Núcleo de Química contribuiu para que essa ciência pudesse ser trabalhada de uma maneira lúdica, visto que os participantes puderam explorar os conceitos de maneira livre, criativa e interessante. Acredita-se ainda que o II JALEQUIN despertou nos estudantes o interesse para a participação e desenvolvimento de novos eventos. 


\section{AGRADECIMENTOS}

Ao Instituto Federal de Minas Gerais, pela possibilidade de desenvolvimento do evento, bem como pela permissão para divulgação dos resultados neste trabalho.

\section{REFERÊNCIAS}

BRASIL. Ministério da Educação. Base Nacional Comum Curricular: educação é a base. Brasília: MEC, 2017. Disponível em:

http://basenacionalcomum.mec.gov.br/images/BNCC_20dez_site.pdf\&gt. Acesso em: 01 abr. 2020.

BRASIL. Ministério da Educação. Parâmetros Curriculares Nacionais (PCNs). Ciências das Naturezas, Matemática e suas tecnologias. Ensino Médio. Brasília: MEC/SEF, 1998. Disponível em: http://portal.mec.gov.br/seb/arquivos/pdf/ciencian.pdf\&gt. Acesso em: 27 mar. 2020.

CUNHA, M. B da. Jogos no Ensino de Química: considerações teóricas para a sua utilização em sala de aula. Química Nova na Escola, v. 34, n. 2, p. 92-98, maio. 2012. Disponível em: http://qnesc.sbq.org.br/online/qnesc34_2/07-PE-53-11.pdf. Acesso em: 11 maio 2020.

FELÍCIO, C. M.; SOARES, M. H. F. B. Da intencionalidade à responsabilidade lúdica: novos termos para uma reflexão sobre o uso de jogos no ensino de Química. Química nova na escola, v. 40, n. 3, p. 160-168, ago. 2018. DOI: http://dx.doi.org/10.21577/01048899.20160124. Disponível em: http://qnesc.sbq.org.br/edicao.php?idEdicao=75. Acesso em: 11 maio 2020.

GARCEZ, E. S. C.; SOARES, M. H. F. B. Um estudo do estado da arte sobre a utilização do lúdico em ensino de Química. Revista Brasileira de Pesquisa em Educação em Ciências, v. 17, n. 1, p. 183-214, abr. 2017. DOI: https://doi.org/10.28976/1984-2686rbpec2017171183. Disponível em: https://periodicos.ufmg.br/index.php/rbpec/article/view/4438. Acesso em: 8 maio 2020.

KISHIMOTO, T. M. O jogo e a educação infantil: jogo, brinquedo, brincadeira e educação. São Paulo, Cortez, 1996.

NASCIMENTO, A. M. S. et al. Vista do ludo das ligações Químicas: um jogo didático no ensino de Química. International Journal Education and Teaching, Recife, v. 1, n. 1, p. 137-157, jan./abr. 2018. DOI: https://doi.org/10.31692/2595-2498.vli01.26. Disponível em: https://ijet-pdvl.com/index.php/pdvl/article/view/26. Acesso em: 8 maio 2020.

NASCIMENTO, E. F. A.; PORTO, M. D. O jogo didático na perspectiva de Vygotsky e a inclusão do estudante no processo de ensino e aprendizagem de Química. In: CONGRESSO DE ENSINO, PESQUISA E EXTENSÃO DA UEG, 3., 2016, Pirenópolis. Anais... Pirenópolis: UEG, 2016. Disponível em:

https://www.anais.ueg.br/index.php/cepe/issue/view/224. Acesso em: 11 maio 2020. 
MESSEDER NETO, H. S.; MORADILLO, E. F. O Lúdico no ensino de Química: considerações a partir da psicologia histórico-cultura. Química Nova na Escola, São Paulo, v. 38, n. 4, p. 360-368, nov. 2016. DOI: http://dx.doi.org/10.21577/0104-8899.20160048. Disponível em: http://qnesc.sbq.org.br/edicao.php?idEdicao=68. Acesso em: 11 maio 2020.

OLIVEIRA, A. S.; SOARES, M. H. F. B. Júri Químico: uma atividade lúdica para discutir conceitos químicos. Química Nova na Escola, São Paulo, v. 21, p. 18-24, maio. 2005. Disponível em: http://qnesc.sbq.org.br/online/qnesc21/v21a04.pdf. Acesso em: 8 maio 2020.

REZENDE, F A. M.; SOARES, M. H. F. B. Jogos no ensino de Química: um estudo sobre a presença/ausência de teorias de ensino e aprendizagem na perspectiva do $\mathrm{V}$ epistemológico de Gowin, Investigações em Ensino de Ciências, v. 24, n. 1, p. 103-121, 2019. DOI: 10.22600/1518-8795.ienci2019v24n1p103. Disponível em: https://www.if.ufrgs.br/cref/ojs/index.php/ienci/article/view/1269. Acesso em: 8 maio 2020.

SILVA, E. K. S.; LIMA, J. P. F.; FERREIRA, M. L. Descobrindo os elementos químicos: jogo lúdico proporcionando uma aprendizagem significativa sobre a tabela periódica. Revista de Pesquisa Interdisciplinar, v. 1, p. 228-237. 2016. DOI:

http://dx.doi.org/10.24219/rpi.v1iEsp.87. Disponível em: http://revistas.ufcg.edu.br/cfp/index.php/pesquisainterdisciplinar/article/view/87. Acesso em: 7 maio 2020.

SOARES, M. H. F. B. Jogos atividades lúdicas no ensino de Química: uma discussão teórica necessária para novos avanços. Revista Debates em Ensino de Química, v. 2, n 2, p. 5-13, Out. 2016. Disponível em: http://www.journals.ufrpe.br/index.php/REDEQUIM/article/view/1311. Acesso em: 7 maio 2020.

\section{DADOS DOS AUTORES}

Nome: Eliane Cristina de Resende

E-mail: eliane.resende@ifmg.edu.br

Currículo Lattes: http://lattes.cnpq.br/0497962402905395

Professora do Departamento de Ciências e Linguagens do Instituto Federal de Minas Gerais Campus Bambuí. Possui graduação em Licenciatura Química pela Universidade Federal de Lavras (2008), Mestrado em Agroquímica (2010), pela Universidade Federal de Lavras. Realizou Doutorado Sandwiche pela University of Guelph de agosto de 2011 á Julho de 2012. Em dezembro de 2012, terminou o doutorado pela Universidade Federal de Lavras, cuja tese recebeu o Prêmio Capes de Tese. Em 2017 realizou Pós-Doutorado na Universitat Autònoma de Barcelona - UAB na área de Química Analítica. Tem experiência na área de Química, com ênfase em aproveitamento de resíduos industriais, preparo de carvão ativado, preparo de catalisadores para processos oxidativos avançados (POA). Recentemente tem desenvolvido projetos sobre Desigualdade de Gênero.

Nome: Priscila Ferreira de Sales

E-mail: priscila.sales@ cefetmg.br

Currículo Lattes: http://lattes.cnpq.br/1577809067615493 
Professora do Departamento de Formação Geral do CEFET/MG- Nepomuceno. Atuou como Professora no Departamento de Ciências e Linguagens (área de Química) do Ensino Básico, Técnico e Tecnológico (EBTT), no Instituto Federal de Educação, Ciência e Tecnologia de Minas Gerais (IFMG) - Campus Bambuí entre 2016 e 2019. Trabalhou como técnica de Laboratório em Química, na Central de Análises e Prospecção Química (CAPQ) da Universidade Federal de Lavras no período de 2014 a 2016. Possui graduação em Química (Licenciatura) pela Universidade Federal de Lavras (2009), mestrado (2011) e doutorado em Agroquímica (2013) pela mesma instituição de ensino.

Nome: Vássia Carvalho Soares

E-mail: vassia.soares@ifmg.edu.br

Currículo Lattes: http://lattes.cnpq.br/2665919411365521

Possui graduação em Engenharia Florestal pela Universidade Federal de Lavras (2003), graduação em Química pelo Centro Universitário de Lavras (2003), mestrado em Ciência Florestal pela Universidade Federal de Viçosa (2007) e doutorado em Ciência e Tecnologia da Madeira pela Universidade Federal de Lavras (2011). Atualmente é professora do Instituto Federal Minas Gerais campus Bambuí.

Nome: Meryene de Carvalho Teixeira

E-mail: meryene.carvalho@ifmg.edu.br

Currículo Lattes: http://lattes.cnpq.br/7723769254941523

Professora efetiva (EBTT) no Instituto Federal de Minas Gerais campus Bambuí onde leciono a disciplina Química III no ensino médio (terceiros anos). Doutora em Agroquímica (UFLA, 2017) com pesquisa desenvolvida na área de eletroquímica aplicando materiais adsortivos em eletrodos de pasta de carbono para determinação de piridina e quinolina em matrizes aquosa e alcoólica. Mestra em Ciências / Agroquímica (UFLA, 2013), com pesquisa também na área de eletroquímica. Licenciada em Química com trabalho de determinação e quantificação de arsênio em matriz aquosa.

Nome: Claudimar Junker Duarte

E-mail: claudimar.junker@ifmg.edu.br

Currículo Lattes: http://lattes.cnpq.br/8065086767122141

Possui graduação em Química (Universidade Federal de Lavras ,2009), mestrado (Universidade Federal de São Carlos, 2011) e doutorado em Química Orgânica (Universidade Estadual de Campinas, 2015). Atualmente está professor no Instituto Federal de Minas Gerais (IFMG/Campus Bambuí). Tem experiência na área de Química, com ênfase em Estrutura, Conformação e Estereoquímica, atuando principalmente nos seguintes temas: análise conformacional, Estereoquímica, Espectroscopia no Infravermelho e de Ressonância Magnética Nuclear e Química Computacional. Mais recentemente tem desenvolvido projetos direcionados ao Ensino de Química. 